Jurnal Inkofar * Volume 1 No. 2, Desember 2018 * ISSN: 2615-3645 (Print) / 2581-2920 (Online)

Tersedia secara online di: http://www.politeknikmeta.ac.id/meta/ojs/

\title{
PERANCANGAN ANIMASI INTERAKTIF MENGENAL SEMBILAN WALI UNTUK USIA SEKOLAH DASAR
}

\author{
Syifa Nur Rakhmah ${ }^{1}$, Feru Adiningrat ${ }^{2}$, Usef Khaerul Abbas ${ }^{3}$ \\ ${ }^{1}$ Sistem Informasi / STMIK Nusa Mandiri Jakarta / syifa.snk@nusamandiri.ac.id \\ ${ }^{2}$ Manajemen Informatika / STMIK Bina Insani / feruadiningrat@binainsani.ac.id \\ ${ }^{3}$ Manajemen Informatika / AMIK BSI Bekasi / usep.abas@gmail.com
}

\begin{abstract}
Currently educational institutions in Indonesia strives to create quality education by applying various learning strategies, including the use of interactive animation as a medium of instruction. Design of interactive animation to know the nine guardians is one form of media content created using Adobe Flash Professional CS5, making it easier for students of Islamic religious education in learning with technology the computer. This strategy is expected to train and enhance students motor nerve as well as introduce students against modern learning technology. On the other hand, the media this learning can help teachers in providing an attractive explanation against the students.
\end{abstract}

Keywords : animation, interactive learning, student

\begin{abstract}
ABSTRAK
Saat ini institusi pendidikan di Indonesia berupaya menciptakan pendidikan yang berkualitas dengan menerapkan strategi pembelajaran yang beragam, salah satunya penggunaan animasi interaktif sebagai media pembelajaran. Perancangan animasi interaktif mengenal sembilan wali merupakan salah satu bentuk media pembelajaran yang dibuat menggunakan Adobe Flash Professional CS5, sehingga memudahkan siswa dalam belajar Pendidikan Agama Islam dengan memanfaatkan teknologi komputer. Strategi ini diharapkan dapat melatih dan meningkatkan saraf motorik siswa serta mengenalkan siswa terhadap teknologi pembelajaran modern. Di sisi lain, media pembelajaran ini dapat membantu guru dalam memberikan penjelasan yang menarik terhadap siswa.
\end{abstract}

Kata Kunci : animasi, pembelajaran interaktif, pelajar

\section{PENDAHULUAN}

Dunia pendidikan di Indonesia terus diperbaiki, sejumlah upaya dilakukan oleh pemerintah termasuk meningkatkan alokasi pendidikan sebesar 20\%, akan tetapi berbagai persoalan terus menghampiri. Berdasarkan Indeks Pembangunan Manusia (IPM) yang dikeluarkan United Nations Development Programme (UNDP) pada 2016, Indonesia meraih angka sebesar 0,689 atau berada pada peringkat 113 dari 188 negara dalam kategori pembangunan manusia menengah. Salah satu sorotan UNDP adalah kesenjangan pendidikan Indonesia yang lebih tinggi dari rata-rata di wilayah Asia Timur dan Pasifik.

Kondisi diatas menjadi tantangan bagi Indonesia dalam pencapaian Tujuan Pembangunan Berkelanjutan (SDGs) yang ditetapkan Persatuan Bangsa Bangsa (PBB) sebagai agenda pembangunan dunia hingga 2030. Khususnya poin keempat mengenai penjaminan kualitas pendidikan yang inklusif dan merata serta meningkatkan kesempatan belajar untuk semua (Asyar: 2011).

Maka dari itu, berbagai institusi pendidikan mulai berupaya menciptakan pendidikan yang berkualitas, namun hal ini terhambat akibat penyampaian materi yang dilakukan guru kepada 
Jurnal Inkofar * Volume 1 No. 2, Desember 2018 * ISSN: 2615-3645 (Print) / 2581-2920 (Online)

Tersedia secara online di: http://www.politeknikmeta.ac.id/meta/ojs/

siswa sangat minim. Guru merasa kesulitan dalam memberikan pemahaman kepada siswa mengenai materi yang disampaikan, khususnya siswa sekolah dasar yang masih suka bermain. Kondisi ini semakin diperburuk dengan kemajuan teknologi yang membuat siswa lebih tertarik dengan games dibandingkan belajar, sehingga prestasi belajar siswa menurun (Rusman: 2012).

Dampak kemajuan teknologi ini yang coba di adopsi untuk membuat suatu media pembelajaran yang lebih baik dan modern, salah satunya perancangan animasi interaktif mengenal sembilan wali yang dibuat menggunakan Adobe Flash Professional CS5 untuk mata pelajaran Pendidikan Agama Islam. Media pembelajaran ini sebagai bentuk strategi penyampaian materi yang lebih modern, sehingga melatih dan meningkatkan saraf motorik siswa serta mengenalkan siswa, selain itu dapat membantu dalam memberikan penjelasan yang menarik terhadap siswa karena dibuat mirip sebuah games (Chandra: 2011).

Meski secara umum materi dalam animasi interaktif ini perlu diketahui oleh semua umat beragama Islam, namun ruang lingkup penggunaan animasi ini hanya untuk siswa sekolah dasar saja.

Pada penelitian sebelumnya Rakhmah (2017) merangkan pada jurnal yang berjudul Sistem Informasi Perpustakaan Bebasis Web Pada SMK Negeri 2 Kota Bekasi bahwa, "kebutuhan teknologi pada dunia pendidikan amatlah penting, dengan dibuatnya sebuah website perpustakaan pada SMK Negeri 2 Bekasi dapat membantu kegiatan belajar mengajar pada sekolah tersebut". Hal ini pula ingin diterapkan oleh penulis kepada siswa sekolah dasar dengan mengimplementasikan animasi interaktif pengenalan sembilan wali.

\section{METODOLOGI PENELITIAN}

Metode penelitian yang digunakan untuk mendapatkan data-data penunjang dalam penelitian ini, diantaranya:

\subsection{Metode Pengembangan Perangkat Lunak}

Dalam pengembangan perangkat lunak, penelitian ini menggunakan model Waterfall. Menurut Sukamto dan M. Shalahuddin (2013: 28) "Model air terjun menyediakan pendekatan alur hidup perangkat lunak secara sekuensial atau terurut dimulai dari analisa, desain, pengkodean, pengujian, dan pendukung (support)"

Adapun lima tahapan yang diterapkan pada penelitian ini, sebagai berikut:

1. Analisa.

Proses analisa kebutuhan perangkat lunak yang dilakukan secara intensif sehingga bisa diketahui perangkat lunak yang dibutuhan oleh developer dan mudah dipahami oleh user. Maka dari itu, perancangan animasi interaktif ini menggunakan Storyboard dalam membuat sketsa gambar yang sesuai dengan naskah, Adobe Flash Professional CS5 dalam pembuatan animasi dan Adobe Photoshop CS6 dalam mengedit gambargambar yang dibutuhkan.

2. Desain.

Proses perancangan struktur antarmuka seperti scene, background, teks dan gambar, menggunakan Storyboard sehingga didapat alur sederhana yang mudah dipahami. Sementara proses perancangan tombol-tombol yang berfungsi sebagai navigasi dilakukan pada Adobe Flash Professional CS5.

3. Pengkodean.

Proses pembuatan kode program menggunakan action script yang sudah disediakan oleh Adobe Flash Professional CS5.

4. Pengujian.

Proses pengujian terfokus pada perangkat lunak saja, dari mulai logic hingga fungsionalnya. Hal ini dilakukan untuk meminimalisir kesalahan (error) dan 
Jurnal Inkofar * Volume 1 No. 2, Desember 2018 * ISSN: 2615-3645 (Print) / 2581-2920 (Online)

Tersedia secara online di: http://www.politeknikmeta.ac.id/meta/ojs/

memastikan keluaran yang dihasilkan sesuai dengan keinginan user. Pada penelitian ini, pengujian dilakukan dengan metode Blackbox Testing.

5. Pendukung.

Proses pendukung atau bisa juga disebut sebagai pemeliharaan (maintenance), tahapan setelah proses implementasi terhadap program dilakukan. Ketika adanya permintaan untuk melakukan perubahan, serta terjadi permasalahan pada aplikasi maka akan dilakukan perbaikan dan mulai dari tahapan awal lagi sesuai urutan metode waterfall.

\subsection{Teknik Pengumpulan Data}

Teknik pengumpulan data dalam penelitian ini adalah:

1. Pengamatan.

Melakukan pengamatan langsung terhadap proses belajar mengajar pada beberapa sekolah dasar di wilayah Bekasi, serta melakukan pengamatan tidak langsung terhadap aplikasi-aplikasi sejenis yang ada di internet, termasuk mengamati aplikasi animasi interaktif yang paling banyak di download dari playstore.

2. Wawancara.

Metode tanya jawab secara langsung dengan beberapa guru sekolah dasar tentang metode pembelajaran yang mereka gunakan serta kendala yang sering ditemui. Selain itu dilakukan diskusi dengan beberapa siswa sekolah dasar mengenai cara belajar yang mereka sukai.

3. Studi Pustaka.

Pencarian sumber referensi yang dilakukan dengan cara membaca buku di perpustakaan mengenai animasi interaktif, panduan menggunakan adobe flash profesional CS5 (Chandra: 2011), dan lain sebagainya, serta mencari referensi tambahan berupa artikel atau e-book di internet yang berkaitan dengan penelitian.

\section{HASIL, ANALISA DAN PEMBAHASAN}

\subsection{Analisa Kebutuhan}

Berdasarkan pengamatan yang dilakukan serta data yang dikumpulkan, maka diperlukan adanya suatu inovasi dalam dunia pendidikan saat ini, khususnya pendidikan bagi siswa sekolah dasar. Media pembelajaran harus diperbaharui, tidak bisa hanya terfokus pada buku bacaan atau alat penunjang seperti papan tulis saja, kemajuan teknologi harus dimanfaatkan guna memberikan cara pembelajaran yang baru dan modern.

Dibuatnya animasi interaktif mengenal sembilan wali menggunakan Adobe Flash Professional CS5 ini, merupakan salah satu bentuk inovasi dengan memanfaatkan kemajuan teknologi terhadap dunia pendidikan sehingga proses belajar mengajar lebih menyenangkan. Di sisi lain, dengan aplikasi animasi interaktif ini selain visual juga dilengkapi dengan audio, sehingga siswa dapat belajar mandiri karena sudah terdapat melihat dan mendengar panduan cara menggunakannya (Mokodaser: 2013).

Sebagai bahan dalam pengambilan data pada program animasi interaktif, penulis menggunakan referensi buku Lismanto (2014).

\subsection{Perancangan Perangkat Lunak}

\subsubsection{Rancangan Storyboard.}

Dalam merancang alur animasi interaktif mengenal sembilan wali, digunakan storyboard agar mudah dipahami. Menurut Enggar (2011) mengemukakan bahwa, "Storyboard merupakan rangkaian gambar ilustrasi yang berusaha menjelaskan bahasa tulisan skenario ke dalam bahasa visual".

Berikut ini adalah rancangan storyboard animasi interaktif mengenal sembilan wali: 
Jurnal Inkofar * Volume 1 No. 2, Desember 2018 * ISSN: 2615-3645 (Print) / 2581-2920 (Online)

Tersedia secara online di: http://www.politeknikmeta.ac.id/meta/ojs/

Tabel 1. Storyboard pada halaman intro

\begin{tabular}{llll}
\hline Visual & \multicolumn{2}{c}{ Sketsa } & Audio \\
\hline Dalam frame & & Intro.mp3 \\
ini terdapat & Gambar & & \\
$\begin{array}{l}\text { tampilan } \\
\text { intro dans } \\
\text { terdapat satu } \\
\text { tombol }\end{array}$ & & \\
navigasi yaitu & & \\
mulai. & & \\
\hline
\end{tabular}

Tabel 2. Storyboard pada halaman menu utama

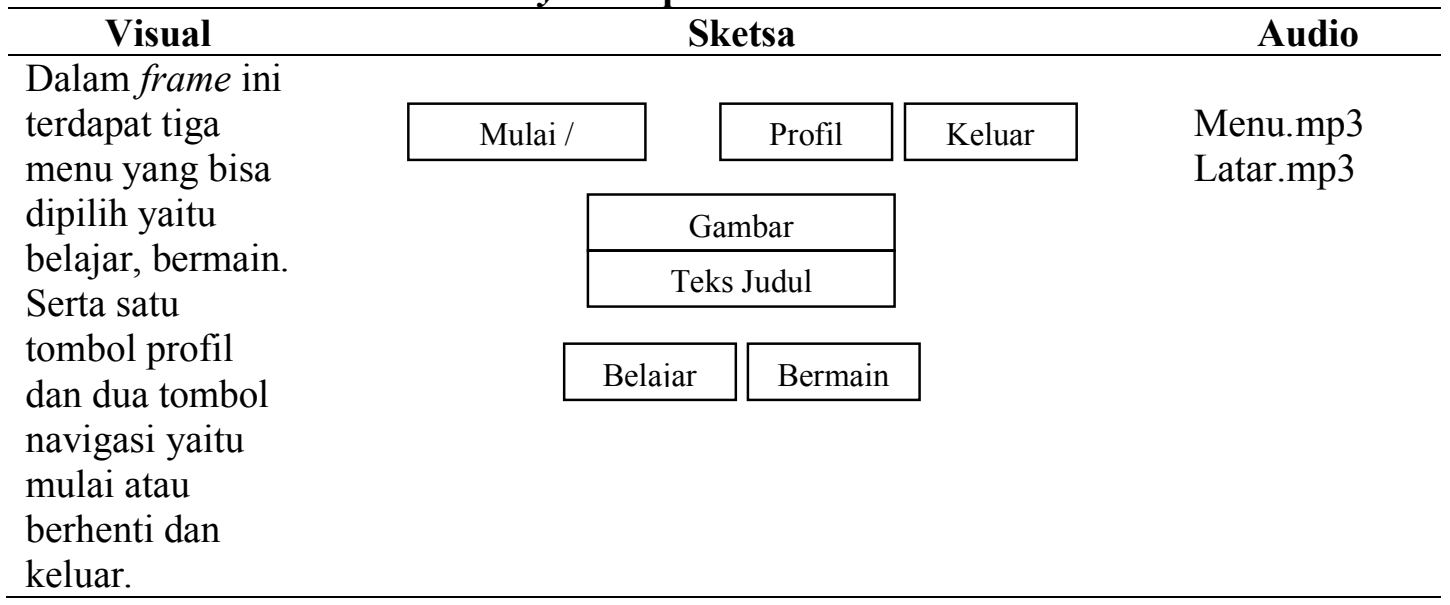

\subsubsection{Rancangan Antarmuka.}

Merancang antarmuka merupakan bagian yang paling penting dalam membangun suatu aplikasi, dikarenakan rancangan ini yang nantinya menjadi tampilan yang akan dilihat oleh user. Dalam merancang antarmuka harus mempertimbangankan segala aspek, salah satunya user friendly. Berikut ini adalah rancangan antarmuka animasi interaktif mengenal sembilan wali.

a. Rancangan antarmuka intro.

Intro merupakan tampilan pembuka saat program pertama kali dijalankan. Pada tampilan ini terdapat satu tombol navigasi mulai untuk masuk ke dalam menu utama.

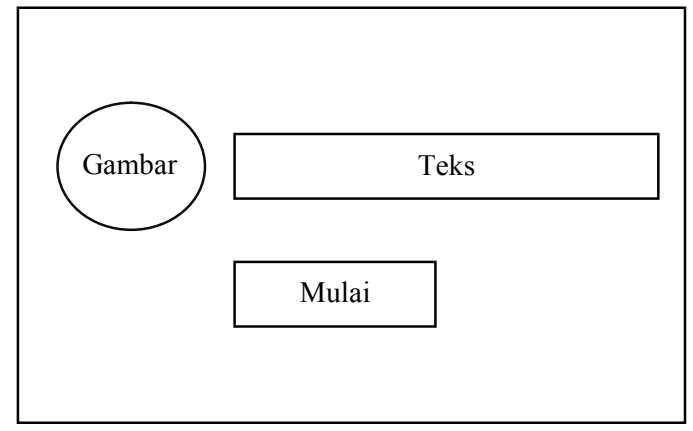

\section{Gambar 1. Rancangan antar muka untuk tampilan intro}


Jurnal Inkofar * Volume 1 No. 2, Desember 2018 * ISSN: 2615-3645 (Print) / 2581-2920 (Online)

Tersedia secara online di: http://www.politeknikmeta.ac.id/meta/ojs/

b. Rancangan antarmuka menu utama.

Pada menu utama ini terdapat dua menu pilihan, pertama menu belajar yang terbagi menjadi dua submenu materi mengenai data diri para wali dan kisah wali, kedua menu bermain yang terbagi menjadi dua submenu mengenai permainan edukasi seperti puzzel gambar dan susun nama. Selain itu terdapat satu tombol profil, dan dua tombol navigasi yaitu tombol mulai atau berhenti musik latar dan tombol keluar dari program.

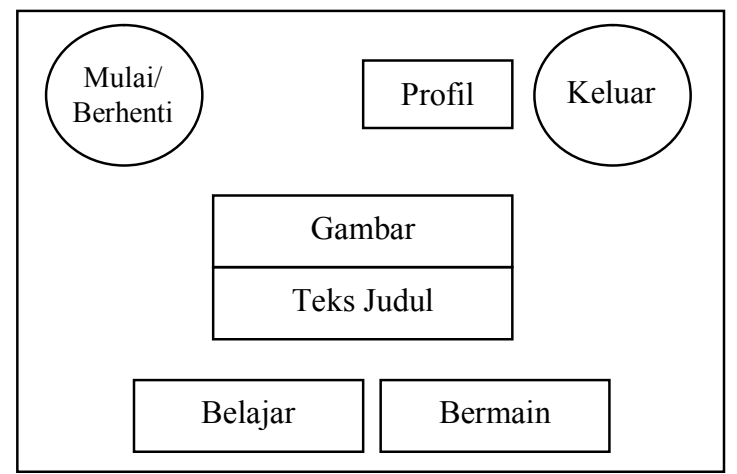

\section{Gambar 2. Rancangan antar muka untuk tampilan menu utama}

\subsection{Implementasi dan Pengujian Unit}

\subsubsection{Implementasi.}

Berikut ini tampilan implementasi rancangan antar muka pada animasi interaktif mengenal sembilan wali.

a.

Tampilan intro.

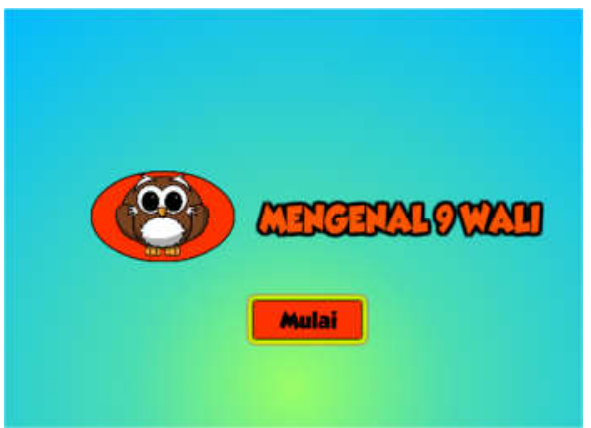

Gambar 3. Tampilan implementasi pada bagian intro

b. Tampilan menu utama.

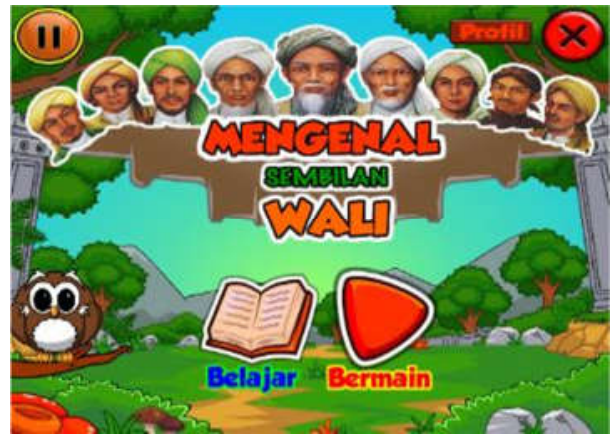

Gambar 4. Tampilan implementasi pada bagian menu utama 
Jurnal Inkofar * Volume 1 No. 2, Desember 2018 * ISSN: 2615-3645 (Print) / 2581-2920 (Online)

Tersedia secara online di: http://www.politeknikmeta.ac.id/meta/ojs/

\subsubsection{Pengujian Unit}

Hasil pengujian unit yang dilakukan dengan menggunakan metode Blackbox Testing.

a. Pengujian terhadap halaman intro.

Tabel 4. Hasil pengujian blackbox testing pada intro

\begin{tabular}{|c|c|c|c|}
\hline Input / Event & Proses & Output/ Next Stage & $\begin{array}{l}\text { Hasil } \\
\text { Pengujian }\end{array}$ \\
\hline $\begin{array}{l}\text { Tombol } \\
\text { "Mulai" }\end{array}$ & $\begin{array}{l}\text { on(press)\{ } \\
\quad \text { gotoAndPlay("Scene } \\
2 ", 1) ; \\
\}\end{array}$ & $\begin{array}{l}\text { Halaman loading yang } \\
\text { menuju menu utama }\end{array}$ & Sesuai \\
\hline
\end{tabular}

b. Pengujian terhadap menu utama

Tabel 5. Hasil pengujian blackbox testing pada menu utama

\begin{tabular}{|c|c|c|c|}
\hline Input / Event & Proses & Output/ Next Stage & $\begin{array}{l}\text { Hasil } \\
\text { Pengujian }\end{array}$ \\
\hline $\begin{array}{l}\text { Tombol } \\
\text { "Belajar" }\end{array}$ & $\begin{array}{l}\text { on(press)\{ } \\
\text { gotoAndPlay(15); }\end{array}$ & $\begin{array}{l}\text { Halaman loading yang } \\
\text { menuju belajar }\end{array}$ & Sesuai \\
\hline $\begin{array}{l}\text { Tombol } \\
\text { "Bermain" }\end{array}$ & $\begin{array}{l}\text { on(press)\{ } \\
\text { gotoAndPlay(105); }\end{array}$ & $\begin{array}{l}\text { Halaman loading yang } \\
\text { menuju bermain }\end{array}$ & Sesuai \\
\hline $\begin{array}{l}\text { Tombol } \\
\text { "Profil"" }\end{array}$ & $\begin{array}{l}\text { on(press) }\{ \\
\text { gotoAndPlay }(80)\end{array}$ & $\begin{array}{l}\text { Halaman loading yang } \\
\text { menuju profil }\end{array}$ & Sesuai \\
\hline $\begin{array}{l}\text { Tombol } \\
\text { "Keluar" }\end{array}$ & $\begin{array}{l}\text { on(press) }\{ \\
\text { gotoAndPlay(45); }\end{array}$ & $\begin{array}{l}\text { Halaman loading yang } \\
\text { menuju halaman keluar }\end{array}$ & Sesuai \\
\hline
\end{tabular}

c. Pengujian terhadap tombol mulai dan berhenti

Tabel 11. Hasil Blackbox Testing Play dan Pause

\begin{tabular}{|c|c|c|c|}
\hline $\begin{array}{l}\text { Input } \\
\text { Event }\end{array}$ & Proses & Output/ Next Stage & $\begin{array}{l}\text { Hasil } \\
\text { Pengujian }\end{array}$ \\
\hline $\begin{array}{l}\text { Tombol } \\
\text { "Mulai" }\end{array}$ & $\begin{array}{l}\text { play.onPress }=\text { function }()\{ \\
\text { if (Pause) }\{ \\
\text { musik.start(posisi, 1); } \\
\text { Pause = false; } \\
\} \\
\text { musik.onSoundComplete } \\
=\text { function }()\{ \\
\text { mainkanMusik }() ; \\
\} ;\end{array}$ & $\begin{array}{ll}\text { Musik } & \text { latar } \\
\text { dimainkan } & \end{array}$ & Sesuai \\
\hline $\begin{array}{l}\text { Tombol } \\
\text { "Berhenti" }\end{array}$ & $\begin{array}{l}\text { stop.onPress = function() }\{ \\
\text { posisi } \\
\text { Math.floor(musik.position/1000); } \\
\quad \text { musik.stop(); } \\
\quad \text { Pause = true; } \\
\} ;\end{array}$ & Musik latar berhenti & Sesuai \\
\hline
\end{tabular}


Jurnal Inkofar * Volume 1 No. 2, Desember 2018 * ISSN: 2615-3645 (Print) / 2581-2920 (Online)

Tersedia secara online di: http://www.politeknikmeta.ac.id/meta/ojs/

\section{KESIMPULAN}

Animasi interaktif mengenal sembilan wali dirancang untuk anak usia sekolah dasar sebagai media pembelajaran pada mata pelajaran Pendidikan Agama Islam dengan memanfaatkan teknologi komputer. Desain tampilan yang lebih berwarna serta adanya tambahan audio menjadikan menjadikan media pembelajaran ini tidak membosankan, terlebih didalamnya ditambahkan suatu games yang membuat para siswa lebih aktif, dan diharapkan dapat melatih dan meningkatkan saraf motorik siswa. Di sisi lain, media pembelajaran ini dapat membantu guru dalam memberikan penjelasan yang menarik terhadap siswa. Berdasarkan hasil dari implementasi dilapangan, animasi interaktif mengenal sembilan wali, merupakan suatu inovasi dalam strategi pembelajaran menggunakan media yang berbeda dan lebih modern, serta jauh lebih disukai oleh para siswa sekolah dasar. Aplikasi ini bisa menjadi pilihan orangtua untuk mengajarkan anak-anaknya dirumah secara mandiri dikarenakan konsep aplikasi yang sederhana, dan mudah dimainkan.

\section{DAFTAR PUSTAKA}

Asyhar, R. 2011. Kreatif Mengembangkan Media Pembelajaran. Jakarta: Gaung Persada (GP) Press Jakarta.

Chandra. 2011. 7 Jam Belajar Interaktif Flash CS5 Untuk Orang Awam. Palembang: Maxicom.

Enggar, Seto. 2011. Visual Storytelling \& Storyboard Teknologi Desain Animasi dan Teknik Animasi V4. Diambil Dari: http://seto.citravision.com/berita-21-visualstorytelling--storyboard--teknologi-desain-animasi--dan-teknik-animiasi-v4.html. (23 Februari 2018).

Lismanto. 2014. Mengenal Para Wali Songo. Islam Cendekia. dilihat 8 Juni 2015. http://www.islamcendekekia.com/2014/09/mengenal-para-wali-songo.html.

Mokodaser, W. 2013. Animasi Dalam Media Pembelajaran. Universitas Klabat. dilihat 9 September 2015. http://www.academia.edu/6220447/ANIMASI_DALAM_ MEDIA_PEMBELAJARAN.

Rakhmah, Syifa Nur. 2017. Sistem Informasi Perpustakaan Bebasis Web Pada Smk Negeri 2 Kota Bekasi. Jurnal Infokar. Vol 1, No 2 (2017). Diambil dari: http://www.politeknikmeta.ac.id/meta/ojs/index.php/inkofar/article/view/11

Rusman. 2012. Belajar dan Pembelajaran Berbasis Komputer. Bandung: CV Afabeta.

Sukamto, Rosa Ariani, dan M. Shalahuddin. 2013. Rekayasa Perangkat Lunak. Bandung: Informatika. 